\title{
Induction of the Plasminogen Activator System Accompanies Peripheral Nerve Regeneration after Sciatic Nerve Crush
}

\author{
Lisa B. Siconolfi and Nicholas W. Seeds \\ Neuroscience Program and Department of Biochemistry and Molecular Genetics, University of Colorado Health Sciences \\ Center, Denver, Colorado 80262
}

Peripheral nerve regeneration is dependent on the ability of regenerating neurites to migrate through cellular debris and altered extracellular matrix at the injury site, grow along the residual distal nerve sheath conduit, and reinnervate synaptic targets. In cell culture, growth cones of regenerating axons secrete proteases, specifically plasminogen activators (PAs), which are believed to facilitate growth cone movement by digesting extracellular matrices and cell adhesions. In this study, the PA system was shown to be specifically activated in sensory neurons after sciatic nerve crush in adult mice. The number of sensory neurons expressing urokinase PA receptor (UPAR) mRNA levels increased above sham levels by $8 \mathrm{hr}$ after crush, whereas the number of sensory neurons expressing uPA and tissue PA (tPA) mRNAs was significantly increased by $3 \mathrm{~d}$ after crush. PA mRNA levels were also increased at the crush

Regeneration of peripheral nerves is dependent on the ability of regenerating neurites to penetrate through structurally altered extracellular matrix (ECM), surrounding tissue, and infiltrating cells at the injury site to reach their synaptic targets. These conditions seem to impede axonal growth and migration of growth cones. Thus, it appears advantageous for regenerating neurites to use proteases, such as the plasminogen activators (PAs), that are capable of degrading ECM and dissolving adhesive contacts to promote growth cone migration and axonal outgrowth. The PAs, tissue PA (tPA) and urokinase PA (uPA), convert the inactive plasminogen to its active serine protease plasmin. Plasmin has broad activity and digests most ECM proteins as well as some cell surface molecules, such as neural cell adhesion molecule (NCAM) (Endo et al., 1998), and activates other proteases, including matrix metalloproteases (Keski-Oja et al., 1992; Murphy and Doherty, 1992).

The plasminogen activators are secreted proteases that bind cell surfaces to localize proteolytic activity to cell-cell and cellsubstratum sites (Vassalli et al., 1985; Ichinose et al., 1986; Knudsen et al., 1986; Plow et al., 1986; Pollanen et al., 1988; Verrall

Received Oct. 31, 2000; revised March 1, 2001; accepted March 14, 2001.

This work was supported by grants from the National Science Foundation (IBN 9630458), the Spinal Cord Research Foundation (2081), and National Institutes of Health (NS09818) to N.W.S., and National Institute of Child Health and Human Development (T32-HD07408) and National Institute of Neurological Disorders and Stroke (T32-NS07083) to L.B.S. We are grateful to Drs. Jay Degen for providing the uPA probe, Keld Dano for the uPAR probe, and S. R. Levinson for use and direction with the confocal microscopy. We also thank Susan Haffke for excellent technical assistance and Becky Norquist for assistance with this manuscript.

Correspondence should be addressed to Dr. Nicholas W. Seeds, Department of Biochemistry and Molecular Genetics, University of Colorado Health Sciences Center, 4200 East Ninth Avenue B-121, Denver, CO 80262. E-mail: Nicholas.Seeds@uchsc.edu.

Copyright (c) 2001 Society for Neuroscience 0270-6474/01/214336-12\$15.00/0 site, with UPA mRNA elevated by $8 \mathrm{hr}$ after crush and tPA and UPAR mRNA levels markedly increased by $7 \mathrm{~d}$. PA-dependent enzymatic activity was significantly increased from 1 to $7 \mathrm{~d}$ after crush in nerves that had been crushed compared with uncrushed nerves. Immunohistochemistry showed that tPA was localized within regenerating axons of the sciatic nerve. There were no significant changes in plasminogen activator inhibitor 1 activity between crush and sham after the injury. These results clearly demonstrated that after injury the PA system was rapidly induced in sensory neurons, where it may play an important role in nerve regeneration in vivo.

Key words: nerve regeneration; sensory neurons; tissue plasminogen activator; urokinase; urokinase receptor; in situ hybridization

and Seeds, 1988, 1989; Pittman et al., 1989). uPA binds to a well characterized receptor (uPAR) on cell surfaces (Estreicher et al., 1989), and this binding enhances uPA activity (Vassalli et al., 1985).

Nerve regeneration is analogous to development in that a recapitulation of axonal outgrowth occurs. Proteins required during axonal development, including GAP-43, tubulin, and actin, are known to be reexpressed or upregulated by peripheral neurons during regeneration (Hoffman and Cleveland, 1988; Meiri et al., 1988; Moskowitz and Oblinger, 1995; Lund and McQuarrie, 1996). Furthermore, PA mRNAs and PA activity are increased in developing embryonic dorsal root ganglia (DRG) and ventral motor neurons of the spinal cord during the period of active axonal growth to their peripheral targets (Sumi et al., 1992; Seeds et al., 1996). The neuronal expression of PA system mRNA is downregulated after axonal contact with synaptic targets. Therefore, it is conceivable that the plasminogen activator system is reactivated in response to nerve injury to facilitate axonal growth. In fact, studies have shown the involvement of PA-dependent activity at the growth cones of regenerating mammalian sensory neurons in culture (Krystosek and Seeds, 1984). These sensory neurons secrete both tPA and UPA and cleave underlying fibronectin while extending their axons (McGuire and Seeds, 1990). The cleaving activity is sensitive to uPA inhibitors (McGuire and Seeds, 1990) and an antibody to uPA (N. W. Seeds, unpublished observations). Pittman (1985) showed that regenerating sympathetic and sensory neurons in culture secrete a uPAlike plasminogen activator and a $\mathrm{Ca}^{2+}$-dependent matrix metalloprotease. An in vivo study has shown increased uPA-dependent activity in the facial nucleus after transection of the rat facial nerve (Nakajima et al., 1996). Cells from dissociated $2 \mathrm{~d}$ postnatal 
murine DRGs in culture show a 75 - to 165 -fold increase in tPA, uPA, and uPAR mRNA while regenerating their axons. These mRNA increases are coincident with the period of maximal axonal outgrowth (Hayden and Seeds, 1996).

Although most studies have demonstrated the involvement of PA proteolytic activity in regenerating sensory neurons in vitro, there has not been an extensive analysis of the PA system in peripheral neurons during in vivo regenerative events. Therefore, the primary aim of this study was to determine whether an induction of the PA system occurs in sensory neurons in vivo after sciatic nerve crush and during subsequent regeneration.

A brief preliminary report of some of these findings has appeared previously (Siconolfi and Seeds, 1997).

\section{MATERIALS AND METHODS}

Surgery and perfusion. Adult C57BL6 mice and C57BL6/129 outbred hybrid mice (backcrossed every 10 generations) were anesthetized with a mixture of $160 \mathrm{mg} / \mathrm{kg}$ ketamine and $12 \mathrm{mg} / \mathrm{kg}$ xylazine or pentobarbital $(50 \mathrm{mg} / \mathrm{kg})$ injected intraperitoneally. The area above the left lower thigh was shaved and sterilized with Betadine and $70 \%$ EtOH. A $1 \mathrm{~cm}$ incision was made in the shaved area over the gluteus maximus muscle and the biceps femoris muscle. The muscles were teased apart with scissor tips, and the sciatic nerve was exposed. For crush injury, the nerve was placed in a 1-mm-wide needle holder and crushed for $20 \mathrm{sec}$ (Glazner et al., 1993, 1994; Navarro et al., 1994). The holder was rotated $90^{\circ}$, and the crush was repeated at the same site. The crush site was marked by placing a 7-0 suture in the epineurium immediately proximal to the crush site. The nerve was replaced under the muscle, and the incision was sutured. The injury site for each animal was kept constant at $45 \mathrm{~mm}$ from the tip of the third digit by overlying a measured thread along the projection of the sciatic nerve. Completeness of the crush was established by examining for the loss of sensory and motor function in the hindlimb of the operated mice. Pinching the hindlimb digits and footpad without eliciting a foot withdrawal and vocalization was noted as loss of sensory and motor function (Devor and Govrin-Lippmann, 1979; Navarro et al., 1994; Verdú and Navarro, 1997). The absence of the toe spreading reflex and lateral leg extension when the mouse was gently lifted by the tail (Gutmann et al., 1942; Azzouz et al., 1996) and total lack of hindlimb movement while ambulating also indicated loss of sensory and motor function. Disruption of axonal integrity after crush was also confirmed by immunostaining sciatic nerve tissue sections taken proximal and distal to the crush site, with mouse anti-neurofilament (NFP) antibody. A reduction of NFP reactivity of distal sections indicated loss of axonal integrity (see Immunofluorescence and confocal microscopy). In sham controls, the sciatic nerve of the right hindlimb was exposed, but no crush was made.

For in situ hybridization experiments, mice were killed at several time points after crush surgery $(0.2 \mathrm{~h}, 3 \mathrm{hr}, 8 \mathrm{hr}, 1 \mathrm{~d}, 3 \mathrm{~d}, 7 \mathrm{~d}$, and $14 \mathrm{~d} ; \mathrm{n} \geq$ 3 for each time point) with an overdose of pentobarbital $(130 \mathrm{mg} / \mathrm{kg}$, i.p.). Immediately after respiratory arrest, the mouse's thoracic cavity was opened, and the body tissues were fixed by cardiovascular perfusion with $4 \%$ paraformaldehyde buffered by $2 \mathrm{ml}$ of $20 \%$ heparin $/ 80 \%$ sodium nitrate pumped through a needle inserted into the left ventricle of the heart. Fixation was completed when the internal organs and extremities were bleached, and the animal became rigid. Immediately after fixation, the intact left and right sciatic nerves were removed from $0.5 \mathrm{~cm}$ distal to the injury site, up to and including DRG L4-6. The tissue was immediately frozen in isopentane $\left(-30^{\circ} \mathrm{C}\right)$. All surgical protocols were Institutional Animal Care and Use Committee approved.

Tissue sectioning. Frozen tissue was embedded in O.C.T. compound (Miles Inc., Elkhart, IN). The crushed nerve and its uncrushed counterpart were mounted and cryostat sectioned together. The $16 \mu \mathrm{m}$ sections were picked up on 3-amino-propyltriethoxysilane-coated RNase-free glass slides.

Plasmids and probes. Plasmid pGuPA is the pGEM-11Zf(+) vector (Promega, Madison, WI) containing a Pst I/SmaI fragment of the mouse uPA cDNA (gift from Dr. J. Degen, Children's Hospital Research Foundation, Cincinnati, $\mathrm{OH}$ ). The insert contains $400 \mathrm{bp}$ of the noncoding $3^{\prime}$ uPA mRNA sequence (nucleotides 1638-2039). Plasmid p50A/1 (gift from Dr. K. Dano, Rigshospitalet, Copenhagen, Denmark) is the pBluescript KS ${ }^{(+)}$vector (Stratagene Cloning Systems, La Jolla, CA) containing a $5^{\prime} \mathrm{Xho} I$ fragment of mouse uPAR cDNA (nucleotides 1-366).
Plasmid pGtPA (Friedman and Seeds, 1995) contains a 515 bp EcoRI/ PstI fragment of mouse tPA (nucleotides 805-1319) in the pGEM-3Z vector (Promega).

After purification and linearization of the plasmid DNA templates, sense and antisense ${ }^{35} \mathrm{~S}$-UTP riboprobes were synthesized using rNTPs and the appropriate RNA polymerase, SP6, T7, or T3 (Promega) at $37^{\circ} \mathrm{C}$ (Hayden and Seeds, 1996). The products were purified on spin columns (Boehringer Mannheim, Indianapolis, IN), electrophoresed in a $50 \%$ urea-5\% polyacrylamide gel, and exposed to X-OMAT film to verify size and integrity.

In situ hybridization. In situ hybridization was performed using the procedure of Simmons et al. (1989) as described previously by Friedman and Seeds (1995). Sections were fixed in freshly prepared $4 \%$ paraformaldehyde for $10 \mathrm{~min}$, washed 3 times in $1 \times \mathrm{PBS}$, rinsed in $0.1 \mathrm{M}$ triethanolamine, and acetylated in acetic anhydride. After dehydration in a series of EtOH washes, slides were hybridized with a tPA, uPA, or uPAR ${ }^{35}$ S-cRNA riboprobe at a concentration of $5 \times 10^{-6} \mathrm{cpm} / \mathrm{ml}$ for $15 \mathrm{hr}$ at $60^{\circ} \mathrm{C}$. After hybridization, the slides were washed in a series of $4 \times$ SSC washes, followed by a series of SSC washes containing dithiothreitol, with the final wash in $0.1 \times \mathrm{SSC}$ for $30 \mathrm{~min}$ at $65^{\circ} \mathrm{C}$. The slides were dehydrated in EtOH, coated with Kodak liquid emulsion NTB-2 (Rochester, NY) and stored in a dark box at $4^{\circ} \mathrm{C}$ for 3-4 weeks. As negative controls, ${ }^{35} \mathrm{~S}$-labeled sense probes were used, and showed only background levels. In situ hybridization of DRG neurons was analyzed using NIH Image software to obtain cell and grain count densities. A tPA, uPA, or uPAR mRNA-labeled cell was defined as a cell displaying a grain density $2 \times$ the background level. Cells were counted within 0.02 $\mathrm{mm}^{2}$ unit areas, and results are reported as number of labeled cells per unit area. In addition, the total number of cells was counted in each 0.02 $\mathrm{mm}^{2}$ unit area to determine the percentage of labeled cells per unit area. Neurons were distinguished by their pale nuclei, in contrast to the chromatin-dense Schwann and glial cells in these Giemsa-stained in situ hybridized sections. This distinction was confirmed by anti-NCAM versus anti-S-100 and anti-GFAP immunoreactivity in some sections.

Zymography. Gel zymography was adapted from the procedure described by Heussen and Dowdle (1980). Ten percent polyacrylamide-SDS gels were copolymerized with casein $(1 \mathrm{mg} / \mathrm{ml}$; Sigma, St. Louis, MO) and plasminogen $(2.5 \mathrm{U} / \mathrm{ml}$; Chromogenix AB, Molndal, Sweden). Control gels were prepared similarly but without added plasminogen. Mice were killed by $\mathrm{CO}_{2}$ narcosis at $0.2 \mathrm{~h}, 3 \mathrm{hr}, 8 \mathrm{hr}, 1 \mathrm{~d}, 3 \mathrm{~d}$, and $7 \mathrm{~d}(\mathrm{n} \geq 3$ for each time point) after crush surgery. One centimeter of sciatic nerve including the crush site and the comparable site of its contralateral uncrushed counterpart were removed and immediately homogenized in $10 \mathrm{~mm}$ Tris- $\mathrm{Cl}, \mathrm{pH}$ 6.8. Tissue was normalized for protein concentration using the Lowry method (Lowry et al., 1951). Serial concentrations of homogenate and known amounts of tPA (Genentech, San Francisco, CA) were loaded onto the gels and electrophoresed. After electrophoresis, the SDS was extracted from the gel using $2.5 \%$ Triton X-100, and the gel was incubated for $16 \mathrm{hr}$ in $0.1 \mathrm{M}$ Tris, $\mathrm{pH} 8.1$, at $37^{\circ} \mathrm{C}$, followed by staining with $0.125 \%$ Coomassie blue in $50 \% \mathrm{MeOH} / 10 \%$ acetic acid. Destaining with the same solvent revealed transparent zones of lysis against the dark protein background at $\mathrm{M}_{\mathrm{r}} 65$ and $43 \mathrm{kDa}$ corresponding to tPA and uPA, respectively. The uPA band was blocked by $1 \mathrm{~mm}$ amiloride, an inhibitor of uPA activity that was added to the $0.1 \mathrm{M}$ Tris buffer during the incubation at $37^{\circ} \mathrm{C}$. The proteolyzed bands were quantified using a Molecular Dynamics Computing Densitometer (Sunnyvale, CA), in which 0.8 IU recombinant tPA standard equaled 3000 densitometric units.

Reverse zymography. The procedure for reverse zymography was adapted from the protocol described by Pittman and Patterson (1987). Nerve tissue was removed and electrophoresed as described for zymography; however, known amounts of the PA inhibitor-1 (PAI-1) (American Diagnostica, Greenwich, CT), were electrophoresed on the same gel as the homogenates. SDS was extracted after electrophoresis with $2.5 \%$ Triton X-100 for $30 \mathrm{~min}$. The gels were incubated in $20 \mathrm{~mm}$ Tris, $\mathrm{pH} 8.1$, containing $2 \mathrm{IU} / \mathrm{ml}$ human uPA (American Diagnostica) for $2 \mathrm{hr}$ at room temperature, followed by two rinses in $\mathrm{dH}_{2} \mathrm{O}$, and then incubated for 18 hr at $37^{\circ} \mathrm{C}$ in $10 \mathrm{~mm}$ Tris, $\mathrm{pH} 8.1$. Exposure of the gels to uPA caused the conversion of plasminogen in the gel to plasmin, which in turn degraded the casein. Inhibition of the uPA blocked the conversion of plasminogen to plasmin, as visualized by dark bands on a transparent gel after staining with $0.125 \%$ Coomassie blue in $50 \% \mathrm{MeOH} / 10 \%$ acetic acid and destaining with the same solvent. Bands were quantified using a Molecular Dynamics Computing Densitometer, in which 0.3 IU recombinant PAI-1 standard equaled 20 densitometric units. 

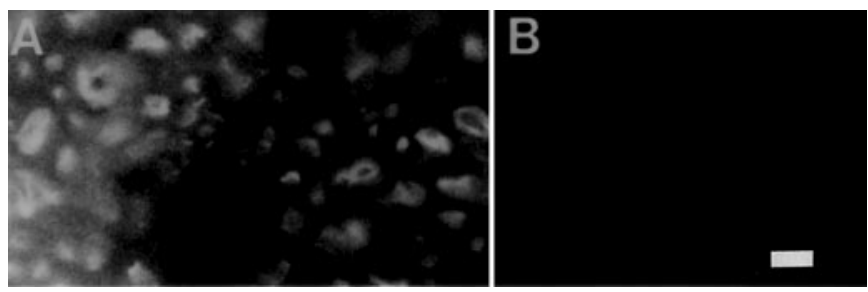

Figure 1. NFP immunostaining $3 \mathrm{~d}$ after crush and sham surgery. Completeness of the sciatic nerve crush surgery was verified by showing the absence of NFP in sections of nerve distal to the crush site, $3 \mathrm{~d}$ after crush surgery $(B)$ compared with sections of the companion sham sciatic nerve $(A)$ in which axons are filled with NFP. Loss of NFP reactivity distal to the crush site confirms that crush injury destroyed axonal integrity and continuity. Scale bar, $8 \mu \mathrm{m}$.

Immunofluorescence and confocal microscopy. Sciatic nerves were removed from mice as described in the perfusion method. The nerve was sectioned transversely in $10 \mu \mathrm{m}$ cryostat sections. The sections were rinsed with PBS, treated with blocking solution ( $4 \%$ goat serum $+0.3 \%$ Triton X-100 in PBS) for $1 \mathrm{hr}$ at room temperature, then reacted with a 1:100 dilution of a polyclonal rabbit anti-mouse tPA antibody (Verrall, 1989) and a 1:50 dilution of a mouse monoclonal anti-NFP (recognizing the 68 and $200 \mathrm{kDa}$ forms) antibody (Zymed, San Francisco, CA) at $4^{\circ} \mathrm{C}$ for $24 \mathrm{hr}$. After they were rinsed several times with PBS, the sections were incubated for $1 \mathrm{hr}$ at room temperature with a solution of goat anti-rabbit IgG Alexa Fluor 568 (1:200; Molecular Probes, Eugene, OR) and donkey anti-mouse FITC (1:200; Jackson ImmunoResearch, West Grove, PA), then coverslipped with Vectashield (Vector Laboratories, Burlingame, CA). The images were viewed with a Nikon Eclipse PCM2000 confocal microscope using a $60 \times$ objective, and images were collected with Simple PCI digital program after balancing red/green laser intensity.

Other sciatic nerve transections were immunostained with rat antineutrophil (1:25; Biosource International, Camarillo, CA), mouse antiMAC-1 (1:25; hybridoma M1/70 American Type Tissue Collection, Rockville, MD), mouse anti-NFP, or rabbit anti-mouse tPA. The same staining procedure was followed using goat anti-rat FITC (1:50; TAGO, Inc., Burlingame, CA), donkey anti-mouse FITC (1:200; Jackson ImmunoResearch), and goat anti-rabbit IgG Alexa Fluor 568, respectively, as secondary antibodies. The sections were visualized using a Zeiss fluorescence microscope or Nikon confocal microscope. The tissue stained with anti-NFP was taken from the areas immediately proximal and distal to the crush site and analyzed to verify the completeness of crush injury.

Dorsal root ganglia were also tPA immunostained. After perfusion, DRGs L4-6 were removed from mice, post-fixed for $30 \mathrm{~min}$ in paraformaldehyde, and embedded in O.C.T. compound. Sensory ganglia from crushed nerve and their uncrushed counterparts were cryostat sectioned at $12 \mu \mathrm{m}$ intervals and mounted on the same slides. Sections were stained as described for tPA antibody staining for sciatic nerve sections and viewed with a Zeiss fluorescence microscope.

\section{RESULTS}

\section{Crush surgery verification}

On injury to peripheral nerve, the neuronal cell bodies contributing to the damaged nerve respond to the insult in various ways. One of the most noted changes is a decrease in the production and anterograde transportation of NFP (Greenberg and Lasek, 1988; Oblinger and Lasek, 1988). Consequently, axonal continuity and transport are disrupted by the crush, and the portion distal to the lesion is no longer supplied with NFP. To verify that our crush surgery caused a complete discontinuity in the axons of the sciatic nerve, sections of the nerve from crush and sham-operated animals were immunostained using a mouse monoclonal antibody against NFP (Fig. 1). Sections distal (Fig. 1B) to the crush site displayed no NFP reactivity at $3 \mathrm{~d}$ after crush surgery compared with sections of the companion sham sciatic nerve (Fig. $1 A$ ), thus confirming that the crush was complete.

\section{Sensory neuron expression of PA system mRNAs}

Our previous study (Hayden and Seeds, 1996) showed that there was a significant increase in tPA, uPA, and UPAR mRNA in dissociated $2 \mathrm{~d}$ postnatal DRG sensory neurons during the regeneration of their axons in culture. This increase coincided with the period of maximal axonal elongation, which suggested that PAs were involved in the process of regeneration. To determine whether similar increases are seen in vivo during peripheral nerve regeneration, in situ hybridization using ${ }^{35}$ S-cRNA probes for mRNAs of the PA system was applied to L4-6 DRGs and sciatic nerve tissue sections from adult mice after nerve crush. Results were quantified by determining the number and percentage of labeled cells within a unit area (see Materials and Methods). The previous study (Hayden and Seeds, 1996), analyzing PA mRNA in cultured mammalian sensory neurons, showed tPA mRNA primarily in small sensory neurons and uPA mRNA restricted mainly to large sensory neurons. To determine whether an analogous condition existed in vivo, labeled cells were analyzed within two populations of DRG neurons: small (8-20 $\mu \mathrm{m}$ diameter) and large ( $\geq 21 \mu \mathrm{m}$ diameter) cells. Glial cells were defined as small dark-stained cells with an elongated nucleus and were eliminated from the counting on the basis of these criteria. Statistical analysis compared ganglia from crushed nerve with sham using a paired $t$ test with $n \geq 3$.

Unoperated control ganglia display few labeled cells. Of the small neuronal cells in unoperated ganglia, $\sim 4-5 \%$ are labeled with tPA, uPA, or uPAR mRNAs (Table 1). Similarly, 10-17\% of large neuronal cells in unoperated ganglia are labeled with tPA, uPA, or uPAR mRNAs. A significant upregulation in uPAR mRNA was first detected in crushed (Fig. $2 A, B$ ) but not sham (Fig. $2 C$ ) sensory ganglia $8 \mathrm{hr}$ after injury. Figure 2, $A$ and $B$, clearly show the increase in uPAR mRNA in sensory ganglia of crushed sciatic nerve. A strong signal was evident in both large and small sensory ganglia neurons (Fig. $2 A$, arrows, $B$ ) compared with the companion sham ganglia (Fig. $2 C$ ). Quantification of the increases in UPAR mRNA-labeled cells in small and large sensory neurons (Table 1 ) of the DRG showed a 2.0-fold increase above sham for small neurons and a 2.5-fold increase above sham for large neurons. uPA and tPA mRNA expression was also apparent in both large and small sensory neurons (Fig. 2D, E, G,H, arrows). Although the number of uPA and tPA mRNA-labeled cells was elevated in sensory ganglia of crushed nerve as early as $8 \mathrm{hr}$ after injury (Fig. 2D,E,G,H), the labeled cell numbers were not significantly different from sham animals (Fig. $2 F, I$, Table 1). One day after crush, the numbers of uPAR mRNA-labeled cells in the DRG were still significantly elevated above sham levels for both small and large cells (data not shown). The first significant increase in the number of UPA and tPA mRNA-labeled cells in both cell populations of the crushed DRG compared with sham DRG was seen at day 3 (Table 1). The increase in tPA mRNA-labeled cells in crushed DRG was 2.4-fold greater than sham for small neurons and 2.0-fold greater than sham for large neurons. Ganglia of crushed nerves showed an increase in uPA mRNA-labeled cells over sham by 1.6-fold for small neurons and 1.8-fold for large neurons. The numbers of cells expressing uPAR mRNA also remained elevated in each cell population: 1.8 -fold above sham in small neurons and 2.0-fold above sham in large neurons (Table 1). The numbers of tPA, uPA, and UPAR mRNA-labeled cells were 
Table 1. In situ hybridization labeled cell counts

\begin{tabular}{|c|c|c|c|c|c|c|}
\hline & Small cells & & & Large cells & & \\
\hline \multicolumn{7}{|c|}{ Unoperated } \\
\hline $\mathrm{tPA}$ & \multicolumn{3}{|l|}{$3.16 \pm 0.78$} & \multicolumn{3}{|l|}{$2.47 \pm 0.49$} \\
\hline uPA & \multicolumn{3}{|l|}{$2.76 \pm 0.71$} & \multicolumn{3}{|l|}{$3.04 \pm 0.23$} \\
\hline \multirow[t]{2}{*}{ uPAR } & \multicolumn{3}{|l|}{$3.14 \pm 0.32$} & \multicolumn{3}{|l|}{$4.21 \pm 0.15$} \\
\hline & Crush & Sham & $p$ & Crush & Sham & $p$ \\
\hline \multicolumn{7}{|l|}{$8 \mathrm{hr}$} \\
\hline $\mathrm{tPA}$ & $10.69 \pm 1.77$ & $11.13 \pm 2.19$ & & $6.15 \pm 2.17$ & $4.20 \pm 1.53$ & \\
\hline uPA & $8.60 \pm 1.90$ & $8.89 \pm 2.60$ & & $4.85 \pm 0.15$ & $4.68 \pm 1.68$ & \\
\hline uPAR & $14.22 \pm 0.97$ & $7.21 \pm 0.77$ & $<0.001$ & $9.29 \pm 0.95$ & $3.75 \pm 0.38$ & 0.05 \\
\hline \multicolumn{7}{|l|}{$3 \mathrm{~d}$} \\
\hline tPA & $13.31 \pm 0.85$ & $5.62 \pm 2.00$ & 0.015 & $9.48 \pm 1.30$ & $4.51 \pm 1.50$ & 0.031 \\
\hline uPA & $24.00 \pm 2.00$ & $15.1 \pm 2.10$ & 0.003 & $6.40 \pm 0.97$ & $3.60 \pm 0.42$ & 0.017 \\
\hline uPAR & $14.85 \pm 0.77$ & $8.23 \pm 0.60$ & 0.003 & $7.28 \pm 0.67$ & $3.32 \pm 0.86$ & 0.006 \\
\hline \multicolumn{7}{|l|}{$7 \mathrm{~d}$} \\
\hline $\mathrm{tPA}$ & $18.05 \pm 1.62$ & $8.40 \pm 0.84$ & 0.001 & $15.94 \pm 2.17$ & $5.68 \pm 0.79$ & 0.008 \\
\hline uPA & $20.14 \pm 1.82$ & $9.17 \pm 0.73$ & 0.012 & $18.77 \pm 1.53$ & $5.89 \pm 0.49$ & 0.012 \\
\hline uPAR & $26.17 \pm 5.80$ & $10.56 \pm 0.80$ & 0.05 & $21.27 \pm 1.40$ & $6.51 \pm 0.79$ & 0.02 \\
\hline \multicolumn{7}{|l|}{$14 \mathrm{~d}$} \\
\hline $\mathrm{tPA}$ & $11.31 \pm 1.66$ & $7.40 \pm 0.95$ & & $7.85 \pm 1.26$ & $6.33 \pm 1.33$ & \\
\hline uPA & $12.86 \pm 1.11$ & $9.50 \pm 0.85$ & 0.01 & $9.39 \pm 1.59$ & $5.65 \pm 1.50$ & \\
\hline uPAR & $15.10 \pm 2.10$ & $11.10 \pm 1.30$ & & $6.43 \pm 1.10$ & $5.56 \pm 1.40$ & \\
\hline
\end{tabular}

$\overline{\text { Analysis of in situ hybridization by labeled cell density showed PA mRNA upregulation in sensory ganglia of crushed sciatic }}$ nerve. Values are expressed as the mean number of labeled cells $/ 0.02 \mathrm{~mm}^{2} \pm \mathrm{SEM}$. Labeled cells were defined as displaying a grain density $2 \times$ the background level. Neurons of the DRG were divided into two populations on the basis of size: large neurons have a diameter of $\geq 21 \mu \mathrm{m}$; small cells have a diameter $>8 \mu \mathrm{m}<21 \mu \mathrm{m}$. $p$ values are given when paired $t$ test analysis of sham versus crushed at a given time point $(n \geq 3)$ is significant $(p \leq 0.05)$. uPAR mRNA levels in ganglia of crushed nerves are significantly elevated above sham as early as $8 \mathrm{hr}$ in both cell populations and remain elevated up to $7 \mathrm{~d}$ after crush. tPA and uPA mRNA levels in ganglia of crushed nerve are significantly increased above sham in both large and small sensory neurons by $3 \mathrm{~d}$.

continually higher than sham through $7 \mathrm{~d}$ after sciatic nerve crush (Table 1), with the most dramatic differences in labeled cell numbers and percentage of labeled cells seen at $7 \mathrm{~d}$. At day 7 , the number of cells expressing tPA mRNA in small sensory neurons of the crush ganglia was 2.2-fold higher than sham, and in the large sensory neurons the numbers were increased up to 2.8 -fold above sham. uPA mRNA-labeled cells in small sensory neurons of crushed ganglia were increased 2.2-fold above sham, and in large sensory neurons, they were 3.2-fold above sham. The number of uPAR mRNA-labeled cells in small sensory neurons was 2.5 -fold higher in crush compared with sham ganglia and 3.3-fold higher than sham in large sensory neurons of crushed ganglia. The percentage of neurons expressing PA mRNA also increased dramatically by $7 \mathrm{~d}$. Twenty-eight percent of small neurons expressed tPA mRNA, 31\% expressed uPA mRNA, and $40 \%$ expressed uPAR mRNA compared with $13.1,14$, and $16 \%$, respectively, in sham ganglia. In large sensory neurons, $66 \%$ were tPA labeled, $78 \%$ were uPA labeled, and $88 \%$ were UPAR labeled compared with 24,24 , and $27 \%$, respectively, in sham ganglia. The number of labeled cells for all mRNAs returned toward control levels by $14 \mathrm{~d}$ after crush.

Sensory ganglia from unoperated animals was also analyzed for PA mRNA expression and compared with sham ganglia (Table 1). The number of labeled cells in sham often exceeded that seen in ganglia from unoperated animals; this was probably indicative of the injured sensory nerve endings in the surrounding skin and muscle resulting from the sham surgery.

\section{PA system mRNA expression and PA activity at the crush site}

PA mRNA signal was also detected at the crush site (Fig. 3). At $8 \mathrm{hr}$, only uPA mRNA was found localized at the crush site (Fig. $3 A$ ). The in situ uPA mRNA appeared somewhat diffuse at the crush site, but there are several areas of concentrated signal associated with small cells (Fig. $3 A$, arrows). Sham nerves (Fig. $3 B, D, F)$ displayed very little PA mRNA at $8 \mathrm{hr}$. Immunostaining with anti-neutrophil and anti-MAC-1 antibodies (Fig. 4, $A$ and $B$, respectively) showed reactive cells at the crush site as early as $1 \mathrm{~d}$ after nerve crush. There was an increase of the inflammatory cells after crush and sham surgery (data not shown), but the infiltration was more enhanced after nerve crush. Neutrophils were present at the crush site as shown (Fig. $4 A$ ) by bright staining of individual cells. Macrophages also appear at the crush site, and smaller areas of staining in Figure $4 B$ revealed macrophage processes within the tissue.

tPA and uPAR mRNA signals at the crush site were not observed until $7 \mathrm{~d}$ after injury (Fig. 5, $B$ and $C$, respectively). Sham nerves at $7 \mathrm{~d}$ (data not shown) were similar to that shown at $8 \mathrm{hr}$. By $14 \mathrm{~d}$ after crush, there was a noticeable increase in tPA mRNA distal to the crush site compared with the area proximal to the crush site (Fig. 6). The tPA signal proximal (Fig. $6 A, p, B$, prox) to the crush was similar to background levels, whereas the distal (Fig. $6 A, d, B$, dis) segment showed a large increase in grain density. This signal probably reflected 
Figure 2. Upregulation of PA mRNA 8 hr after crush surgery. In situ hybridization shows significant upregulation of uPAR mRNA in large and small sensory neurons of DRGs from crushed sciatic nerve $(A$, arrows, $B)$ compared with sham ganglia $(C)$. uPA mRNA is also apparent in both large and small sensory neurons of ganglia with a crushed sciatic nerve ( $D, E$, arrows), as well as some of the sham sensory neurons $(F)$. tPA mRNA is apparent in small $(G$, arrows $)$ and larger $(H$, arrows) sensory neurons of ganglia with a crushed sciatic nerve and in some sham sensory ganglia neurons (I). Scale bar: $A, C, D, F, G, I, 50 \mu \mathrm{m} ; B$, $E, H, 25 \mu \mathrm{m}$.
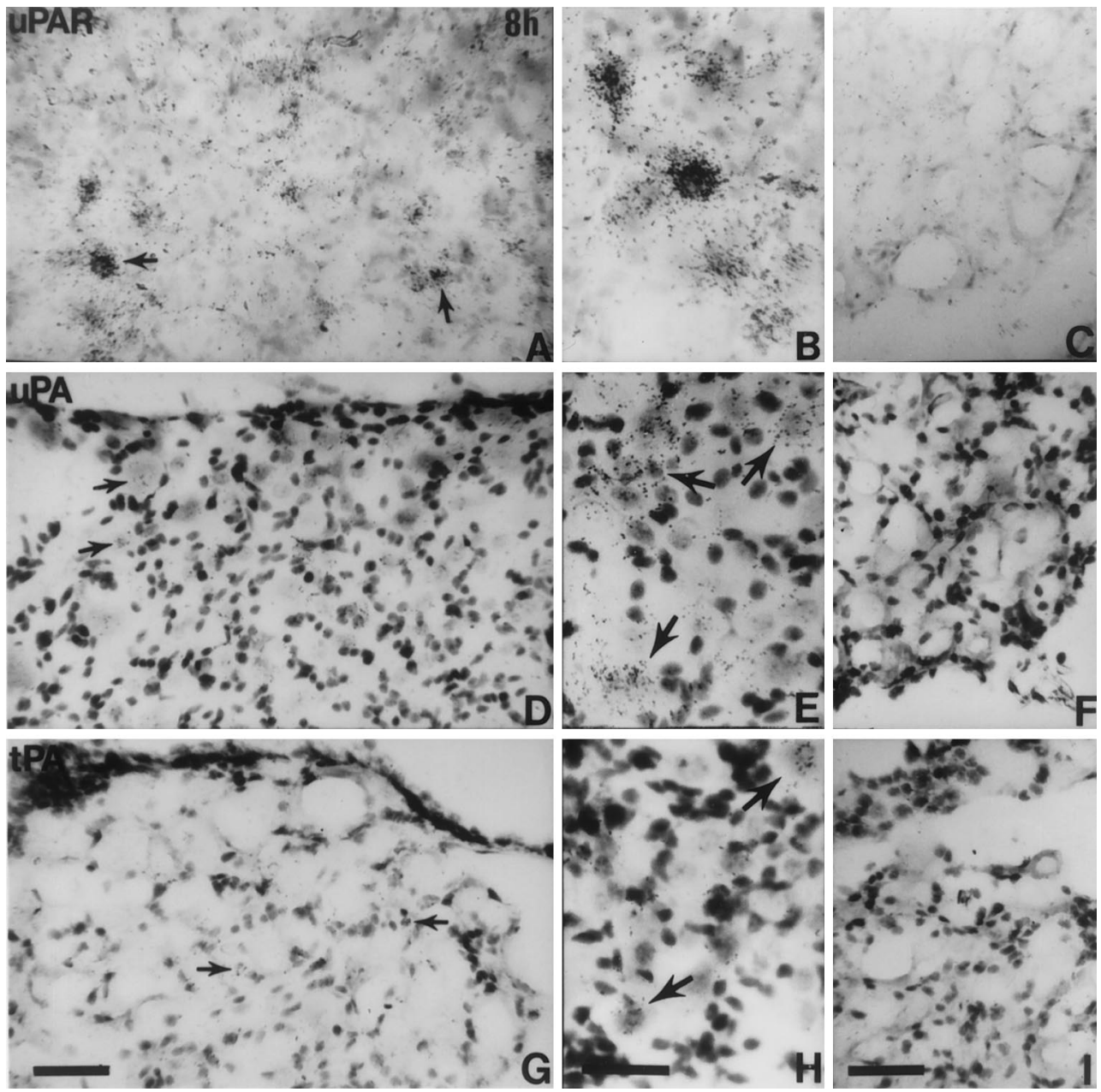

Figure 3. PA mRNA at the crush site $8 \mathrm{hr}$ after crush injury. In situ hybridization shows that uPA mRNA $(A)$ increases in small cells (arrows) at the crush site by 8 hr after injury compared with sham $(B)$. tPA $(C)$ and uPAR $(E)$ mRNAs are not elevated at this time compared with sham ( $D$, tPA; $F$, uPAR). Scale bar, $50 \mu \mathrm{m}$.
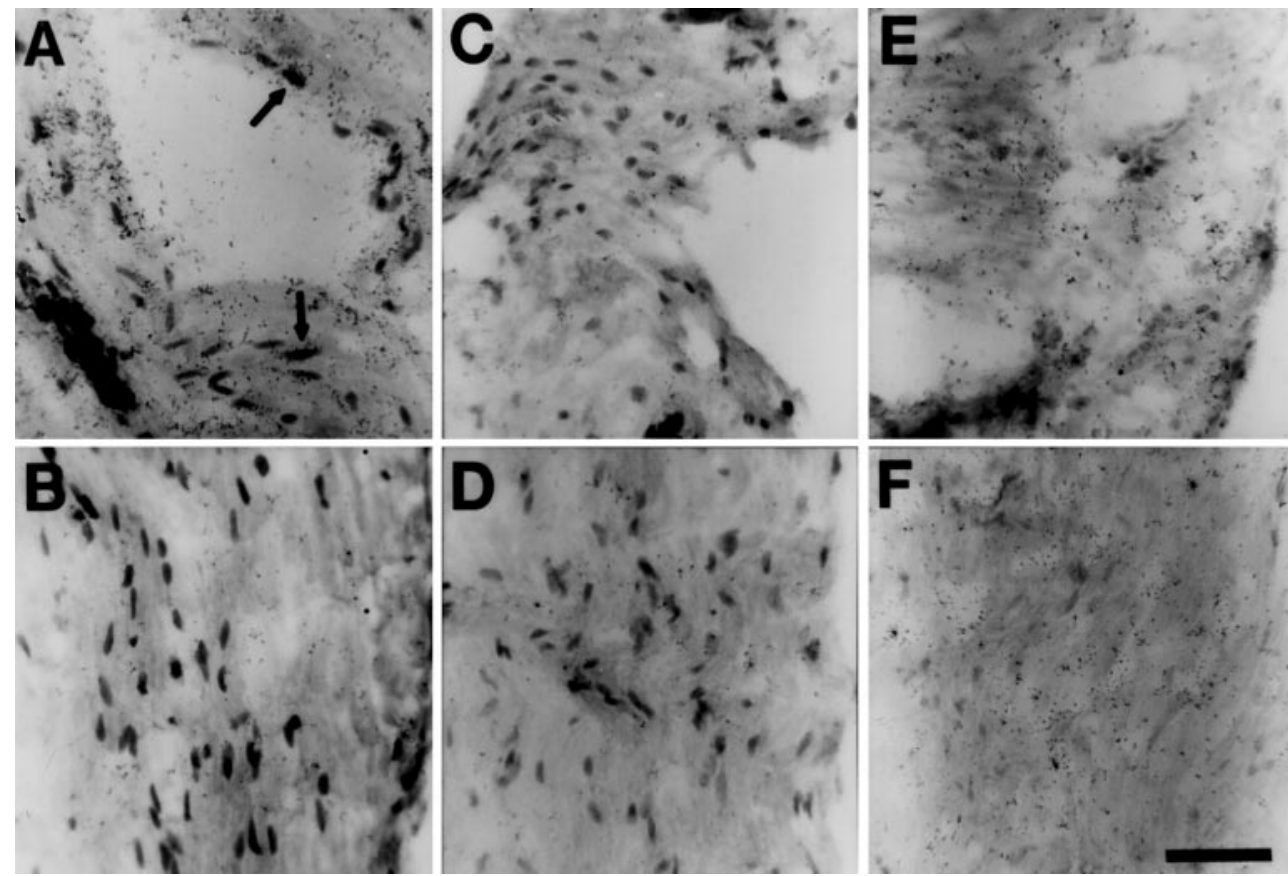


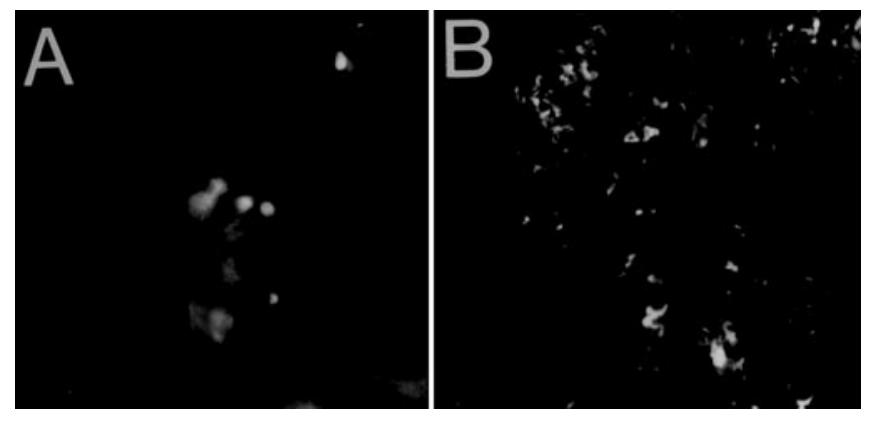

Figure 4. Reactive cells at the crush site after sciatic nerve crush injury. Sciatic nerve cross sections were immunostained with anti-neutrophil antibody and anti-MAC- 1 antibody. Both neutrophils and macrophages are seen at the crush site within $1 \mathrm{~d}$ after crush. $A$, Immunostaining with anti-neutrophil antibody shows bright spots of neutrophil cells $1 \mathrm{~d}$ after crush. $B$, MAC-1, a macrophage cell surface antigen, labels macrophage processes in the plane of the tissue and processes extending into the tissue at different focal levels.

an upregulation of tPA mRNA in proliferating and migrating Schwann cells, identified by their small size and elongated shape, along the regenerating nerve. tPA signal in the sham counterpart nerve was similar in intensity to the signal seen in the proximal portion of the crushed nerve.

To determine whether PA mRNA levels were accompanied by an increase in PA activity, zymography was used to assess PAdependent activity around the crush site at several time points after crush injury (Fig. 7). Only very low levels of uPA and tPA activity could be detected in unoperated controls. By $3 \mathrm{hr}$ after crush, uPA activity was increased significantly above sham levels as shown by $t$ test analysis $(p=0.02)$. Crush-induced uPA activity was again elevated to levels that were significantly above sham by $1 \mathrm{~d}$ after injury $(p=0.012)$. The increase in uPA activity was maintained for up to $7 \mathrm{~d}$ after crush $(3 \mathrm{~d}, p=0.008 ; 7 \mathrm{~d}, p=0.05)$. tPA-dependent activity at the crush site exceeded sham levels by $1 \mathrm{~d}$ after crush and remained upregulated for up to $7 \mathrm{~d}(1 \mathrm{~d}, p=$ 0.034; $3 \mathrm{~d}, p=0.006 ; 7 \mathrm{~d} p=0.004)$.

\section{tPA protein expression in DRG and axons of crushed sciatic nerve}

The elevated PA mRNA and activity at the crush site within $24 \mathrm{hr}$ after crush may reflect upregulation by infiltrating cells such as neutrophils and macrophages (Fig. 4). However, the PAdependent activity at later times ( $3 \mathrm{~d}, 7 \mathrm{~d})$ may be derived from sensory neurons responding to the crush injury. After damage to the nerve, the DRG cell bodies increased production of the PA proteins, as suggested by the in situ hybridization data, and transported the proteases to the regenerating growth cones near the crush site. Figure 8 shows crushed (Fig. $8 A$ ) and sham (Fig. $8 B$ ) sensory ganglia $3 \mathrm{~d}$ after surgery stained with anti-mouse tPA antibody. There was a noticeable difference in intensity of tPA reactivity between crush and sham ganglia. Crush sensory ganglia displayed an increased reactivity, within the sensory neuron cell bodies (arrow) and among supportive cells (i.e., glia and fibroblasts), or associated with matrix surrounding the neurons (arrowheads). The tPA immunoreactivity within the surrounding areas of the sensory neuron cell bodies may also reflect tPA protein secretion from the neurons. Within the neurons of the crushed sensory ganglia, tPA immunoreactivity was seen as distinct points, suggesting a vesicular packaging of the protein (Lochner et al., 1998). Sham ganglia displayed less tPA immuno-
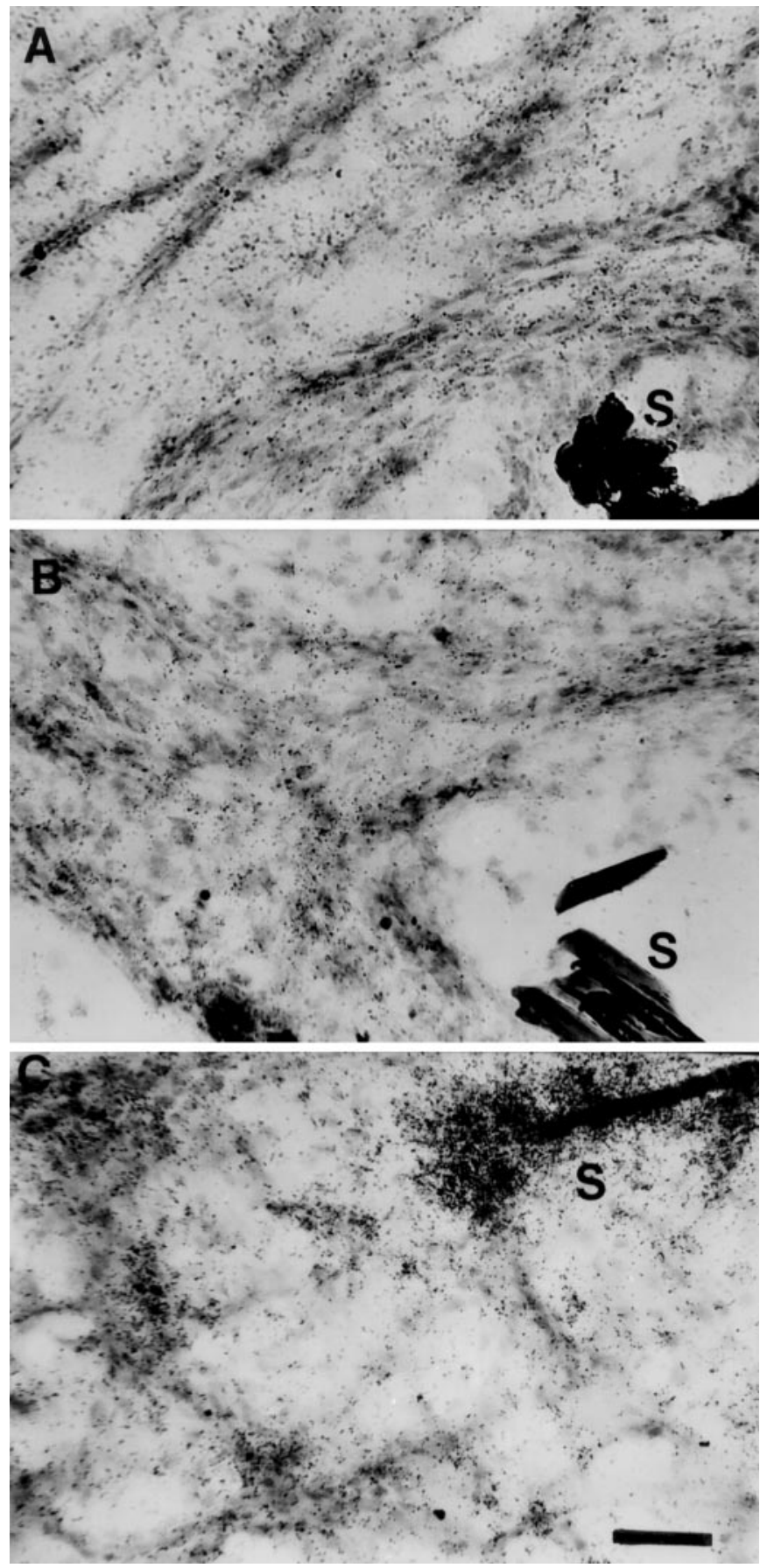

Figure 5. PA mRNA at the crush site $7 \mathrm{~d}$ after crush injury. uPA $(A)$, tPA $(B)$, and uPAR $(C)$ mRNAs are elevated around the crush site $7 \mathrm{~d}$ after injury. Sutures $(S)$ placed in the epineurium during surgery mark the crush site. Scale bar, $20 \mu \mathrm{m}$.

reactivity, and most of the protein appeared to be localized with the supportive cells of the sensory ganglia (Fig. 8B). Unfortunately, a suitable uPA antibody is not available, and thus localization of uPA protein could not be determined.

To determine whether the sciatic nerve axons were actively transporting tPA protein in response to crush injury, cross sections of sciatic nerve were immunostained with both tPA and NFP antibodies. Confocal microscopy of cross sections 50-150 $\mu \mathrm{m}$ proximal to the crush site revealed strong reactivities for tPA (red) and NFP (green) at both 3 and $7 \mathrm{~d}$ after crush (Fig. 9). 
Figure 6. In situ hybridization shows increased expression of tPA mRNA distal to the crush site at $14 \mathrm{~d}$ after injury. The tPA mRNA increase seen distal to crush probably reflects upregulation in Schwann cells along the regenerating nerve. $A$, Overview of crushed sciatic nerve. Suture $(S)$ placed in the epineurium during surgery marks the crush site $(d=$ area of nerve distal to crush site; $p=$ area of nerve proximal to crush site). $B$, Enlarged view of the box in $A$ where area of nerve distal to crush site (dis) folds back on an area of nerve proximal to crush site (prox). Scale bar, $20 \mu \mathrm{m}$.

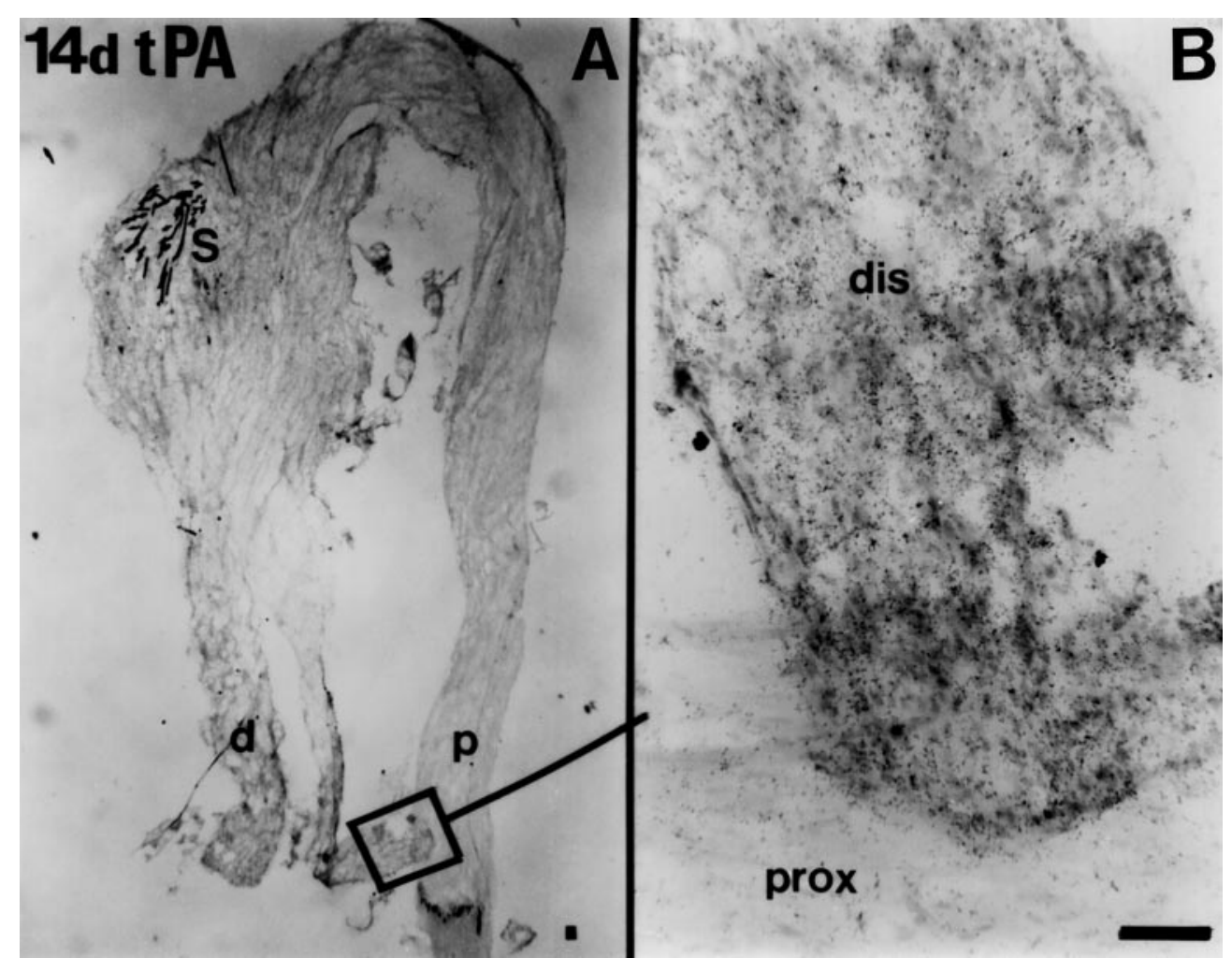

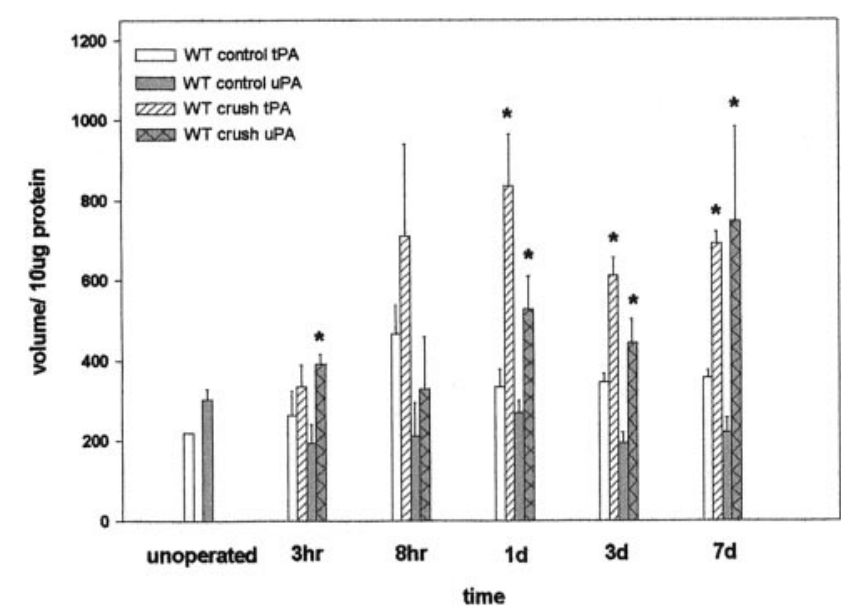

Figure 7. PA-dependent activity in crush and control (sham + unoperated) sciatic nerve. tPA (white bars) and uPA (gray bars) activities were assayed by gel zymography at each of the time points. Lytic zones on zymographs were analyzed and quantified by densitometric scanning using known amounts of recombinant tPA standard (0.8 IU rtPA $=3000$ densitometric volumes). Values are expressed as the volume of lysis (mean $\pm \mathrm{SEM} ; n \geq 3$ ). Crush (bars with diagonal lines) activity for each PA was compared with sham activity (at each time point) by $t$ test analysis. uPA (bars with triangle lines) activity is elevated above sham at $3 \mathrm{hr}$, again at $1 \mathrm{~d}$, and up to $7 \mathrm{~d}$. tPA activity increases above sham by $1 \mathrm{~d}$ and continues through $7 \mathrm{~d}$. ${ }^{*} p \leq 0.05$.

Closer analysis showed that at 3 d, tPA colocalized (Fig. 9A, yellow) with NFP within myelinated axons and was expressed to a lesser extent in the supportive cells (i.e., Schwann cells and fibroblasts). Sham nerve showed little or no colocalization of signals, with some tPA reactivity merely in areas surrounding myelinated axons (Fig. 9B). An enlarged view of crushed sciatic nerve at day 3 (Fig. 9G) clearly showed tPA protein within the axons of the regenerating nerve. At day 7 (Fig. 9H), several axons displayed a punctate pattern of tPA staining within axons of regenerating sciatic nerve, suggesting vesicular packaging of the protein (Lochner et al., 1998). At day 7, tPA was also seen in regenerating axons $\sim 125 \mu \mathrm{m}$ distal to the crush site (Fig. 10A) showing that the protein was axonally transported after crush injury into regenerating axons. Sham nerve at day 7 showed very little reactivity above background levels (Fig. 10B). Thus, tPA protein was upregulated and specifically localized within axons of the regenerating sciatic nerve.

\section{PA inhibitor activity at the crush site}

Because inhibitors are an integral part of controlling proteolytic activity and are linked to changes in levels of protease, PA inhibitor activity was assessed after nerve crush by reverse zymography. PAI-1 is a known physiological inhibitor for both tPA and uPA and regulates PA proteolytic activity (Hekman and Loskutoff, 1988). It is expressed by various cell types including endothelial cells, neutrophils, macrophages, and platelets, and is present in plasma and bound to the extracellular matrix (Erickson et al., 1985; Podor and Loskutoff, 1992; Loskutoff et al., 1994; Haj et al., 1995). Thus, induction of PAI-1 activity might also occur after nerve injury, concurrent with the increases seen in PA activity. PAI-1 activity was identified on reverse zymography gels based on its molecular weight (43 kDa) and compared with known amounts of a PAI-1 standard. Some higher molecular weight PAI-1 evident on the gels appeared to be complexed with tPA in tissue removed from the crush site (data not shown). This activity was not quantifiable because bound inhibitor might have decreased activity because of its conformational state. Unbound PAI-1 was also present at the crush site and its activity could be quantified. Desitometric analysis of the free PAI-1 (43 kDa) activity levels showed an increase above sham levels by $1 \mathrm{~d}$ after crush, which then declined by $7 \mathrm{~d}$. However, these values were not 

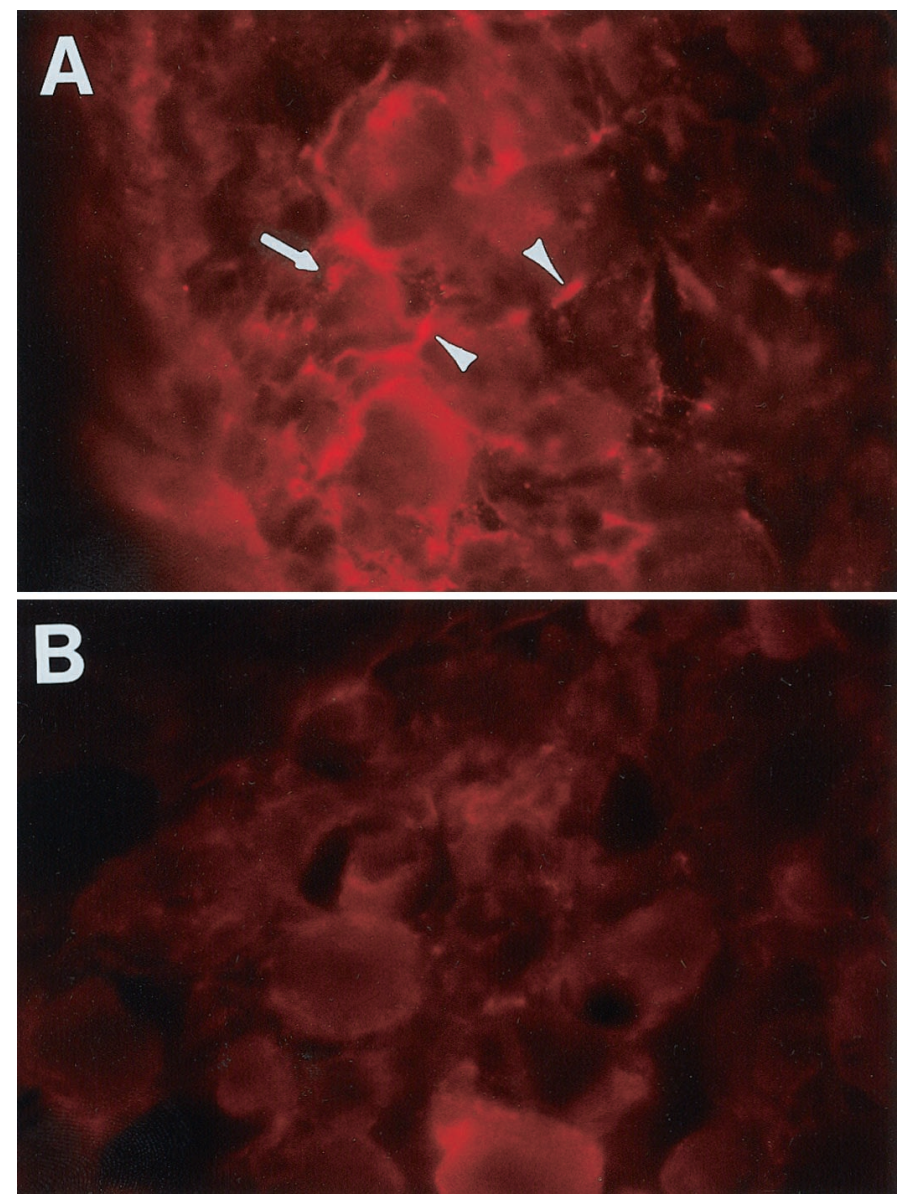

Figure 8. tPA protein expression is upregulated in sensory ganglia neurons of crushed sciatic nerve. Sections of DRG from crush and sham nerve were stained with tPA antibody $3 \mathrm{~d}$ after sciatic nerve crush. $A$, tPA protein is upregulated in response to nerve crush in sensory ganglia. tPA immunoreactivity is localized within sensory neurons (arrow) of crushed sciatic nerve and is clearly associated with matrix or supportive cells (i.e., glia and fibroblasts) of the sensory neurons (arrowheads). $B$, DRG of sham operated sciatic nerve shows considerably less tPA immunoreactivity. The tPA appears to be mostly localized to areas between sensory neurons presumably associated with supportive cells.

statistically different compared with sham and unoperated controls ( $t$ test where $n=3$ and $p \geq 0.05$ at all time points) (Fig. 11). Hence, PAI-1 did not appear to be intimately associated with PA-dependent activity after nerve injury, at least not within the first $7 \mathrm{~d}$.

\section{DISCUSSION}

These results showed clearly that induction of the PA system occurred after peripheral nerve injury. An upregulation of tPA, uPA, and UPAR mRNA occurred in sensory neurons after peripheral nerve injury and remained increased during the early stages of nerve regeneration. Coincident with the increases in mRNA levels was an induction of PA-dependent proteolytic activity at the site of injury and an upregulation of tPA protein inside axons of the regenerating sciatic nerve.

Using in situ hybridization, we demonstrated that tPA, uPA, and UPAR mRNAs were induced in neurons of the sensory ganglia after nerve crush, similar to results obtained with in vitro regeneration (Hayden and Seeds, 1996). Although these in situ hybridization results cannot be compared directly with the quan- titative PCR used in our previous study, the intense grain density of uPAR mRNA, which labels $40 \%$ of the small neurons and up to $88 \%$ of the large neurons, suggests that they may not be much different. Upregulation of uPAR mRNA was evident within large and small sensory neurons and preceded upregulation of UPA and tPA mRNAs (Fig. 2, Table 1). The production of the receptor before its ligand might allow localization of uPAR to specific sites so that uPA can be directed immediately to these points once it is expressed. An early induction of UPAR might also be useful for paracrine interactions with uPA-expressing cells at the injury site. This type of mechanism has been detailed in several invasive tumor cells in which uPAR expressed by the tumor cells binds uPA produced by fibroblast-like stromal cells, thus enhancing ECM degradation and the invasiveness of these tumor cells (Ossowski et al., 1991; Pyke et al., 1991). Additionally, uPAR may also be important for cell signaling. Binding of uPA or the amino-terminal fragment (nonproteolytic domain) of uPA to uPAR on monocytes and fibroblasts has a mitogenic and a chemotaxic effect, both of which involve intracellular events (Besser et al., 1996). Therefore, in our studies the uPAR may not only localize proteolytic activity to specific cell surface sites but might also be involved in conveying signals necessary for regeneration. Furthermore, uPAR has also been shown to interact with $\beta_{1}$ and $\beta_{2}$ integrins and thereby alter integrin function by suppressing integrin-dependent adhesion (Wei et al., 1996). The combination of destabilizing adhesion and localizing uPA-dependent proteolytic activity to cell surface contacts might serve to promote axonal growth cone migration after nerve injury.

The number of uPA and tPA mRNA-labeled cells was elevated in both small and large neurons of the DRG concurrent with a time when newly formed growth cones on regenerating axons are most likely to be traversing the injury site (Hall, 1989; Siconolfi and Seeds, 2001). Presumably, proteolytic activity was required to digest cell-matrix and cell-cell contacts present at the injury site and along the basal lamina encountered by the growth cones. uPA and tPA would sustain the movement of growth cones by converting plasminogen to plasmin, thereby amplifying proteolytic activity toward a broad range of substrates, including laminin, fibronectin, and adhesion molecules (i.e., NCAM), as well as activation of matrix metalloproteases (Zuo et al., 1998). Although in vitro regeneration studies showed tPA expressed primarily in small sensory neurons and UPA in large sensory neurons (Hayden and Seeds, 1996), this phenomenon was not as readily apparent in vivo. In the in vivo condition, it might be advantageous for the regenerating axons of each cell population to use more than one proteolytic device to enhance cleavage and degradation of several types of substrates that are present, such as ECM, adhesion molecules, and injury debris.

In addition to the increase in PA mRNA in the DRGs, there was also an increase of PA mRNA and PA-dependent activity at the crush site. The increase of PA-dependent activity and PA mRNA at the crush site within $1 \mathrm{~d}$ of crush could be attributed to reactive and infiltrating neutrophils, macrophages, fibroblasts, and Schwann cells into the area of injury. All of these cell types express components of the PA system (Eaton et al., 1984; Heiple and Ossowski, 1986; Wilson and Francis, 1987; Grau and Moroz, 1989; Varani et al., 1992; Kung and Lau, 1993; Schafer et al., 1994; Rao et al., 1995; Kindzelskii et al., 1996; Shetty et al., 1996; Xiao et al., 1998). Additionally, we demonstrated with immunostaining that macrophages and neutrophils were present at the crush site within $1 \mathrm{~d}$ after crush injury (Fig. 4). Macrophages have been shown to infiltrate the injury site within $4 \mathrm{hr}$ after rat sciatic 

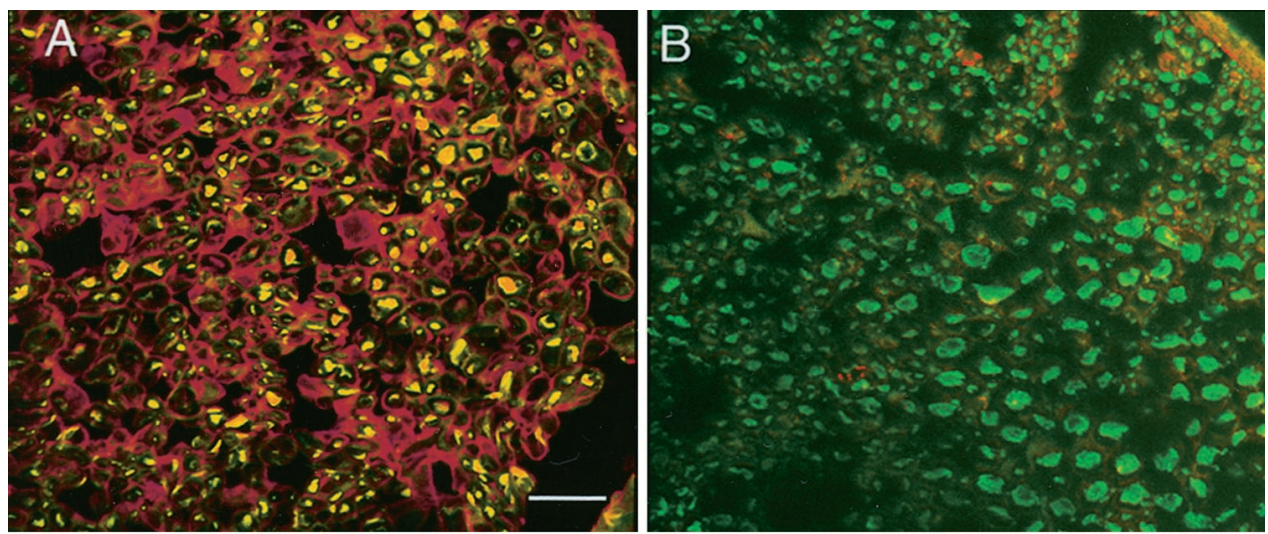

Figure 9. Localization of tPA protein within axons of the regenerating sciatic nerve. Cross sections of sciatic nerve proximal $(50-150 \mu \mathrm{m})$ to the crush site were immunostained with rabbit anti-mouse tPA and mouse anti-NFP antibodies. Images were collected using a Nikon Eclipse PCM2000 confocal microscope. All images were captured using filters for either rhodamine or fluorescein. Color images were merged to show colocalization of the proteins. A, Axons of crushed sciatic nerve $3 \mathrm{~d}$ after injury double labeled with tPA (red) and NFP (green). Colocalization is evident ( yellow) within the axons. Scale bar: $A-F, 16 \mu \mathrm{m}$. $B$, Three day sham nerve double labeled with tPA (red) and NFP (green). Only a few discrete areas show colocalization (yellow) of tPA and NFP. Most tPA reactivity appears to be associated with areas outside of axons, possibly in supportive cells (i.e., Schwann cells). $C$, Same image as $A$ showing only NFP staining of axons. $D$, Same image as $B$ showing only NFP staining of axons. $E$, Same image as $A$ showing only tPA reactivity. $F$, Same image as $B$ showing only tPA reactivity. Notice the dramatic increase in tPA protein after nerve crush compared with the sham. $G$, Enlargement of boxed area in $E$ displays tPA reactivity on grayscale. Areas of tPA immunoreactivity are readily apparent within axons of the regenerating sciatic nerve. Scale bar, 3 $\mu \mathrm{m}$. $H$, Axons of crushed sciatic nerve $7 \mathrm{~d}$ after injury labeled with anti-tPA antibody and displayed on a grayscale. Notice areas of punctate staining within axons, suggestive of vesicular packaging of the protein. Scale bar, $5 \mu \mathrm{m}$.
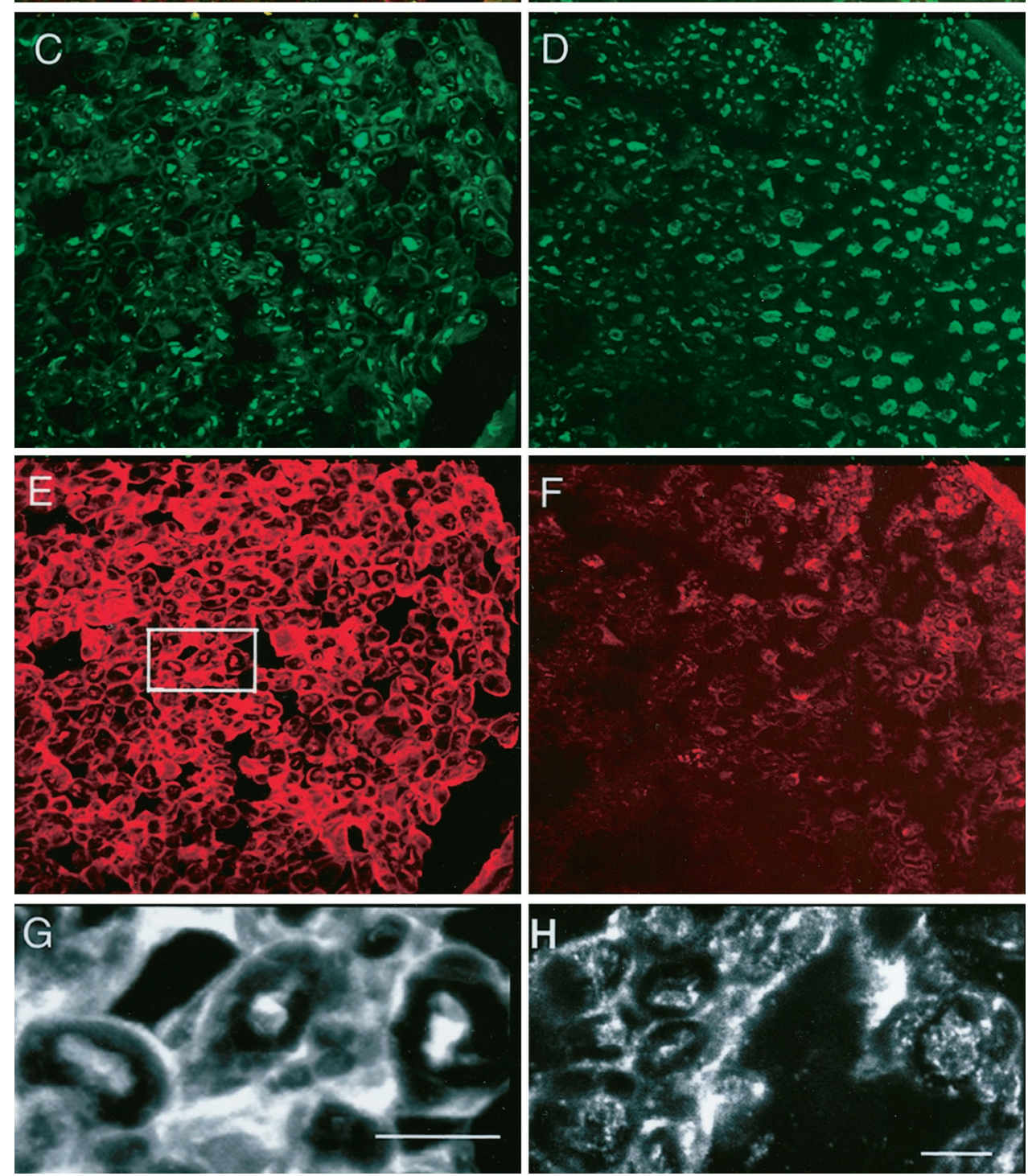

nerve transection, and numbers remain elevated for up to $21 \mathrm{~d}$ (Avellino et al., 1995). These cells can polarize uPA to the leading edge of cell surfaces to facilitate ECM degradation during migration (Estreicher et al., 1990). In addition, activated neutrophils can translocate uPA stored in granules to the plasma membrane surface (Heiple and Ossowski, 1986). Fibroblasts secrete uPA and are released into the injury site because of a breakdown in the blood-nerve barrier that occurs with injury (Oaklander et al., 1987). Furthermore, Schwann cells express tPA (Kalderon, 1984;
Krystosek and Seeds, 1984; Clark et al., 1991). After nerve injury, Schwann cells proliferate, migrate, and align along newly regenerating nerves (Son and Thompson, 1995; Torigoe et al., 1996). Thus, it is probable that induction of tPA mRNA occurred in these reactive Schwann cells during regeneration of the sciatic nerve (Fig. 6). Similarly, Smirnova et al. (1996) showed an increase in tPA activity in distal nerve segments after crush that they attributed to Schwann cells.

The PA-dependent activity that was increased above sham by 

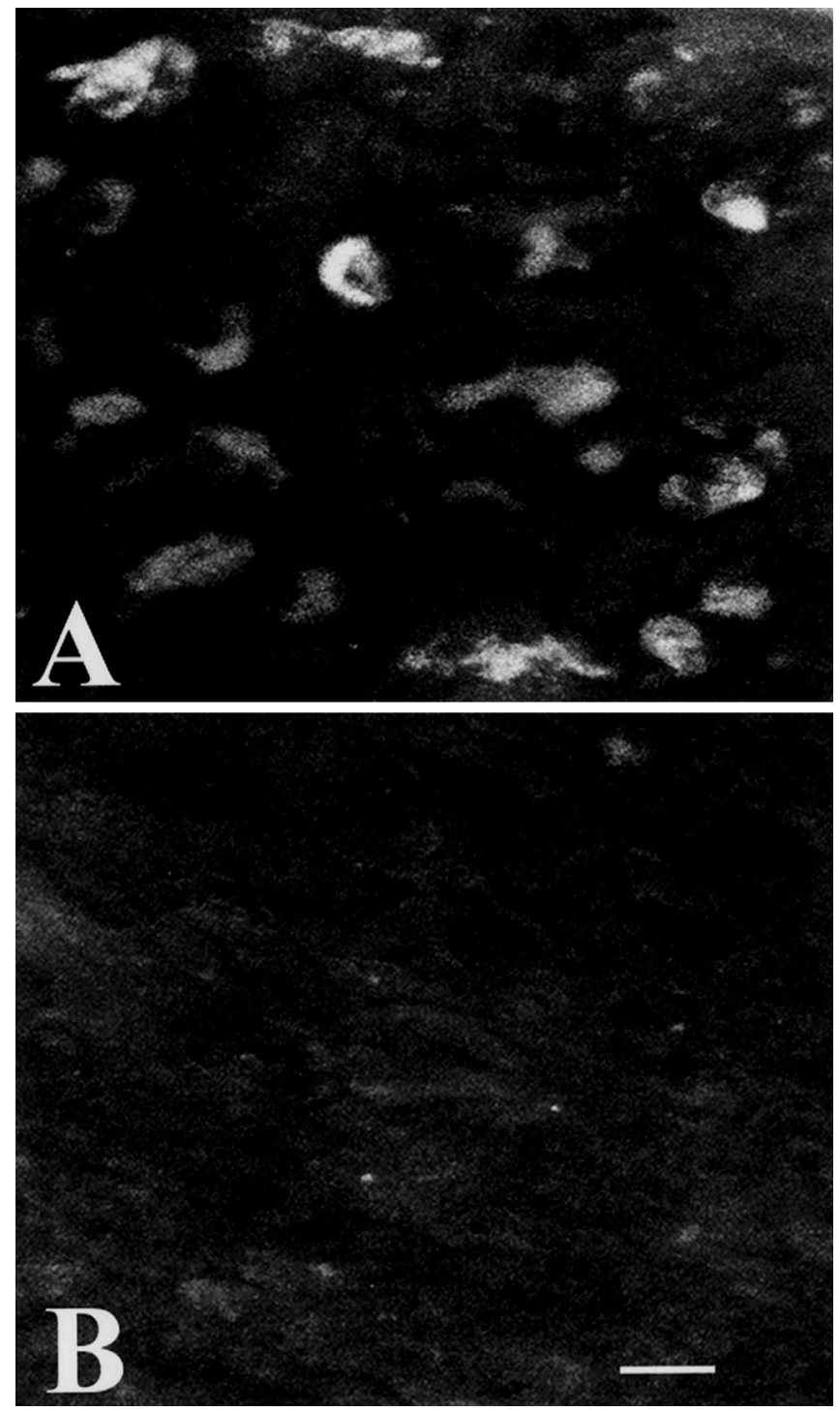

Figure 10. At day 7 tPA protein is also seen in regenerating axons distal to the crush site. Cross sections of sciatic nerve $125 \mu \mathrm{m}$ distal to the crush site were immunostained with rabbit anti-mouse tPA. $A$, tPA protein distal to the crush site appears to be localized within axons of the regenerating sciatic nerve surrounded by dark areas of packed myelin. $B$, Sham nerve shows minimal reactivity. Scale bar, $6 \mu \mathrm{m}$.

days 3 and 7 after crush likely reflected increases in PA protein expression by the sensory neurons of the regenerating sciatic nerve. DRG sensory neurons contributing to the crushed sciatic nerve displayed more intense tPA immunoreactivity after staining with anti-tPA antibody compared with sham DRG sensory neurons (Fig. 8). Confocal microscopy data provides additional support that an important contributor of PA-dependent activity at the crush site was derived from the neurons within the damaged nerve. Double-label immunostaining with tPA and NFP antibodies distinctly demonstrated tPA localized within NFPimmunoreactive axons of the regenerating sciatic nerve at a time concurrent with the upregulation of tPA mRNA (Fig. 9). The staining pattern at day 7 showed areas of punctate reactivity indicative of vesicular packaging. This was in agreement with Lochner et al. (1998) who showed, using a green fluorescent protein-tPA, that vesicular packaged tPA was transported within axons of differentiated PC12 cells and was found at the growth

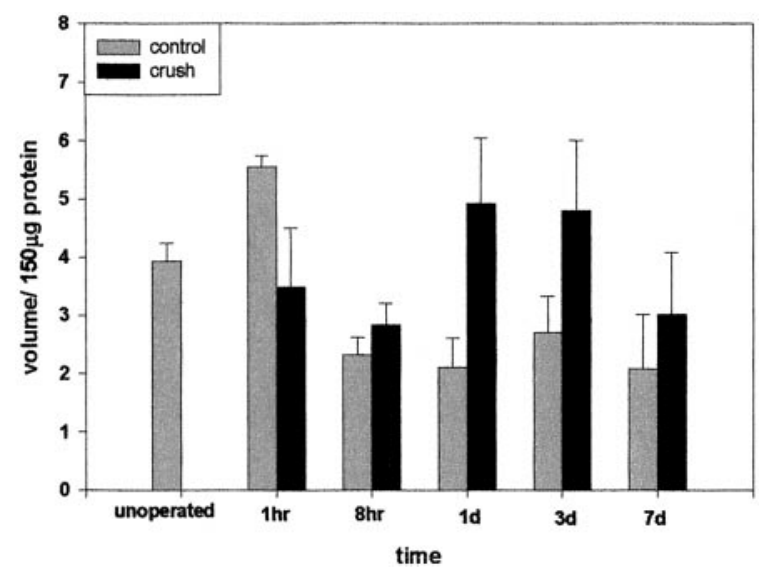

Figure 11. PAI-1 inhibitor activity after crush of the sciatic nerve. PAI-1 activity was assayed by reverse zymography at each time point after crush. Areas of inhibition on gels were analyzed and quantified by densitometric scanning using known amounts of recombinant PAI-1 standard (0.3 IU = 20 densitometric volumes). Values are expressed as the volume of inhibition (mean \pm SEM; $n=3$ ). Crush activity (black bars) was compared with control (sham + unoperated) (gray bars) activity at each time point by paired $t$ test analysis. PAI-1 activity in crushed nerve does not differ significantly from control nerve for up to $7 \mathrm{~d}$.

cones. Furthermore, induced tPA protein is shown here in the more distal regions of the regenerating axon (Fig. 10), where it is poised to facilitate axonal regrowth. Unfortunately, because a suitable antibody for mouse uPA does not currently exist, axonal localization of this protease could not be determined.

Proteolytic activity can also promote regeneration by activation of growth factors. Both uPA and tPA have been shown to cleave and thereby activate the plasminogen-related growth factor, prohepatocyte growth factor/scatter factor (HGF/SF). HGF/SF is a significant growth-promoting and survival factor for sensory and motor neurons (Yamamoto et al., 1997; Maina et al., 1998; Yang et al., 1998). HGF has been shown to promote sympathetic neuron axonal growth and increase the forward rate of sympathetic neurite outgrowth in culture. In addition, neutralization of endogenous HGF by anti-HGF antibody abolished these effects (Yang et al., 1998). In other studies, HGF increased survival time and enhanced neurite outgrowth from nerve growth factor (NGF)-dependent murine DRG neurons grown in dissociated culture (S. Pu and N. Seeds, in preparation). These studies unequivocally implicated $\mathrm{HGF}$ as a growth-promoting factor for specific neurons and thus might be an important downstream target of the PA system after nerve injury.

Serpins play an important role in regulating protease activity. After injury, the protease-inhibitor balance can be modified. Protease inhibitor mRNA and inhibitor secretion have been shown to be induced after nerve injury. In vitro studies showed that TGF $\beta$ causes Schwann cells to increase PAI-1 activity after peripheral nerve injury (Rogister et al., 1993). Recently, Takahashi et al. (2000) showed that differentiated PC12 cells increased PAI-1 mRNA levels in response to NGF. This finding was interesting because NGF synthesis increases dramatically in nonneuronal cells after peripheral nerve injury (Raivich and Kreutzberg, 1993). Protease nexin-1 (PN-1), a thrombin and uPA inhibitor, showed a sevenfold induction in its mRNA in whole preparations of rat sciatic nerve $6 \mathrm{~d}$ after nerve crush. Additionally, PN-1 activity distal to the crush site was maximally induced $7 \mathrm{~d}$ after crush (Meier et al., 1989). This same phenomenon was 
also observed in mouse sciatic nerve (Smirnova et al., 1996). In the present study, we analyzed PAI-1, the major physiological inhibitor of tPA and uPA. PAI-1 activity was not significantly altered after nerve crush (Fig. 11). This finding supported the hypothesis that PAs are upregulated in response to nerve injury and the PA-dependent enzymatic activity observed was not merely a disinhibition of local proteases. Because we assayed PAI-1 activity only up to $7 \mathrm{~d}$ after crush, increases in inhibitor activity may occur at later times (i.e., beyond $7 \mathrm{~d}$ ), thus allowing for an early time window of proteolytic activity without inhibitory interference. Also, PN-1 may play a role and thus needs to be investigated further in this model.

In conclusion, this study demonstrated PA system activation coincident with the process of nerve regeneration in the periphery. We have established that the PA system was activated in response to peripheral nerve injury, and in our companion paper (Siconolfi and Seeds, 2001), we show that PAs facilitate a timely recovery of peripheral nerve function. These findings gain importance because elucidation of the mechanisms that facilitate peripheral nerve outgrowth and regeneration may contribute significantly to stimulating regeneration in the CNS.

\section{REFERENCES}

Avellino A, Hart D, Dailey A, Mackinnon M, Ellegala D, Kliot M (1995) Differential macrophage responses in the peripheral and central nervous system during Wallerian degeneration of axons. Exp Neurol 136:183-198.

Azzouz M, Kennel P, Warter J, Poindron P, Borg J (1996) Enhancement of mouse sciatic nerve regeneration by the long chain fatty alcohol, $N$-Hexacosanol. Exp Neurol 138:189-197.

Besser D, Verde P, Nagamine Y, Blasi F (1996) Signal transduction and the uPA/u-PAR system. Fibrinolysis 10:215-237.

Clark M, Zeheb R, White T, Bunge R (1991) Schwann cell plasminogen activator is regulated by neurons. Glia 4:514-528.

Devor M, Govrin-Lippmann R (1979) Selective regeneration of sensory nerve fibers following nerve crush injury. Exp Neurol 65:243-254.

Eaton D, Scott R, Baker J (1984) Purification of human fibroblast urokinase proenzyme and analysis of its regulation by proteases and protease nexin. J Biol Chem 259:6241-6247.

Endo A, Nagai N, Urano T, Ihara H, Takada Y, Hashimoto K, Takada A (1998) Proteolysis of highly polysialylated NCAM by the tissue plasminogen activator-plasmin system in rats. Neurosci Lett 246:37-40.

Erickson L, Hekman C, Loskutoff D (1985) The primary plasminogen activator inhibitors in endothelial cells, platelets, serum and plasma are immunologically related. Proc Natl Acad Sci USA 82:8710-8714.

Estreicher A, Wohlwend A, Belin D, Schleuning W, Vassalli J (1989) Characterization of the cellular binding site for the urokinase type plasminogen activator. J Biol Chem 264:1180-1189.

Estreicher A, Muhlhauser J, Carpentier J, Orci L, Vassalli J (1990) The receptor for urokinase type plasminogen activator polarizes expression of the protease to the leading edge of migrating monocytes and promotes degradation of enzyme inhibitor complexes. J Cell Biol 111:783-792.

Friedman G, Seeds N (1995) Tissue plasminogen activator mRNA expression in granule neurons coincides with their migration in the developing cerebellum. J Comp Neurol 360:658-670.

Glazner G, Lupien S, Miller J, Ishii D (1993) Insulin-like growth factor II increases the rate of sciatic nerve regeneration in rats. Neurosci 54:791-797.

Glazner G, Morrison A, Ishii D (1994) Elevated insulin-like growth factor (IGF) gene expression in sciatic nerves during IGF-supported nerve regeneration. Mol Brain Res 25:265-272.

Grau E, Moroz L (1989) Fibrinolytic activity of normal blood monocytes. Thromb Res 53:145-162.

Greenberg S, Lasek R (1988) Neurofilament protein synthesis in DRG neurons decreases more after peripheral axotomy than after central axotomy. J Neurosci 8:1739-1746.

Gutmann E, Guttmann L, Medawar P, Young J (1942) The rate of regeneration of nerve. J Exp Biol 19:14-44.

Haj M, Robbie L, Adey G, Bennet B (1995) Inhibitors of plasminogen activator in neutrophils and mononuclear cells from septic patients. Thromb Haemost 74:1528-1532.

Hall S (1989) Regeneration in the peripheral nervous system. Neuropathol Appl Neurobiol 15:513-529.

Hayden S, Seeds N (1996) Modulated expression of plasminogen activa- tor system components in cultured cells from dissociated mouse dorsal root ganglia. J Neurosci 16:2307-2317.

Heiple J, Ossowski L (1986) Human neutrophil plasminogen activator is localized in specific granules and is translocated to the cell surface by exocytosis. J Exp Med 164:826-840.

Hekman C, Loskutoff D (1988) Bovine PAI-1: specificity determinations and comparisons of the active, latent and guanidine-activated forms. Biochemistry 27:2911-2918.

Heussen C, Dowdle E (1980) Electrophoretic analysis of plasminogen activators in polyacrylamide gels containing sodium sulfate and copolymerized substrates. Anal Biochem 102:196-202.

Hoffman P, Cleveland D (1988) Neurofilament and tubulin expression recapitulates the developmental program during axonal regeneration: induction of a specific-beta-tubulin isotype. Proc Natl Acad Sci USA $85: 4530-4533$.

Ichinose A, Takio K, Fujikawa K (1986) Localization of the binding site of tPA to fibrin. J Clin Invest 78:163-169.

Kalderon N (1984) Schwann cell proliferation and localized proteolysis: expression of plasminogen-activator activity predominates in proliferating cell populations. Proc Natl Acad Sci USA 81:7216-7220.

Keski-Oja J, Lohi J, Tuuttila K, Tryggvason K, Vartio T (1992) Proteolytic processing of the 72,000-Da type IV collagenase by urokinase plasminogen activator. Exp Cell Res 202:471-476.

Kindzelskii A, Laska Z, Todd R, Petty H (1996) Urokinase-type plasminogen activator receptor reversibly dissociates from complement receptor type $3\left(\alpha_{\mathrm{m}} \beta_{2}\right.$, CD11/CD18) during neutrophil polarization. J Immunol 156:297-309.

Knudsen B, Silverstein R, Leung L, Harpel P, Nachmam R (1986) Binding of plasminogen to extracellular matrix. $\mathrm{J}$ Biol Chem 261:10765-10771.

Krystosek A, Seeds N (1984) Peripheral neurons and Schwann cells secrete plasminogen activator. J Cell Biol 98:773-776.

Kung S, Lau H (1993) Modulation of the plasminogen activation system in murine macrophages. Biochem Biophys Acta 1176:113-122.

Lochner J, Kingma M, Kuhn S, Meliza C, Cutler B, Scalettar B (1998) Real-time imaging of the axonal transport of granules containing a tissue plasminogen activator/green fluorescent protein hybrid. Mol Biol Cell 9:2463-2476.

Loskutoff D, Sawdey M, Keeton M, Schneiderman J, Lang I, Schleef R (1994) Analysis of PAI-1 gene expression in vivo using in situ hybridization. Ann NY Acad Sci 714:259-264.

Lowry O, Rosenbrough N, Farr A, Randall R (1951) Protein measurement with the folin phenol reagent. J Biol Chem 193:256-275.

Lund L, McQuarrie I (1996) Axonal regrowth upregulates beta-actin and Jun D mRNA expression. J Neurobiol 31:476-486.

Maina F, Hilton M, Andres R, Wyatt S, Klein R, Davies A (1998) Multiple roles for hepatocyte growth factor in sympathetic neuron development. Neuron 20:835-846.

McGuire P, Seeds N (1990) Degradation of extracellular matrix by sensory neurons during neurite outgrowth. Neuron 4:633-642.

Meier G, Spreyer P, Ortmann R, Harel A, Monard D (1989) Induction of glia-derived nexin after lesion of a peripheral nerve. Nature 342:548-550.

Meiri K, Willard M, Johnson M (1988) Distribution and phosphorylation of the growth associated protein GAP-43 in regenerating sympathetic neurons in culture. J Neurosci 8:2571-2581.

Moskowitz P, Oblinger M (1995) Sensory neurons selectively upregulate synthesis and transport of the $\beta_{\mathrm{III}}$-tubulin during axonal regeneration. J Neurosci 15:1545-1555.

Murphy G, Doherty J (1992) The matrix metalloproteinases and their inhibitors. Am J Respir Cell Mol Biol 7:120-125.

Nakajima K, Reddington M, Kohsaka S, Kreutzberg G (1996) Induction of urokinase-type plasminogen activator in rat facial nucleus by axotomy of the facial nerve. J Neurochem 66:2500-2505.

Navarro X, Verdú E, Butí M (1994) Comparison of regenerative and reinnervating capabilities of different functional types of nerve fibers. Exp Neurol 129:217-224.

Oaklander A, Miller M, Spencer P (1987) Early changes in degenerating mouse sciatic nerve are associated with endothelial cells. Brain Res 419:39-45.

Oblinger M, Lasek R (1988) Axotomy-induced alterations in the synthesis and transport of neurofilaments and microtubules in dorsal root ganglion cells. J Neurosci 8:1747-1758.

Ossowski L, Clunie G, Masucci M, Blasi F (1991) In vivo paracrine interaction between urokinase and its receptor: effect on tumor cell invasion. J Cell Biol 115:1107-1112.

Pittman R (1985) Release of plasminogen activator and a calciumdependent metalloprotease from cultured sympathetic and sensory neurons. Dev Biol 110:91-101.

Pittman R, Patterson P (1987) Characterization of an inhibitor of neuronal plasminogen activator released by heart cells. J Neurosci 7:2664-2673.

Pittman R, Ivins J, Buettner H (1989) Neuronal plasminogen activators: cell surface binding sites and involvement in neurite outgrowth. J Neurosci 9:4269-4286. 
Plow E, Freaney D, Plescia J, Miles L (1986) The plasminogen system and cell surfaces: evidence of plasminogen and urokinase receptors on the same cell type. J Cell Biol 103:2411-2420.

Podor T, Loskutoff D (1992) Immunoelectron microscopic localization of the type 1 plasminogen activator inhibitor in the extracellular matrix of transforming growth factor-beta-activated endothelial cells. Ann NY Acad Sci 667:46-49.

Pollanen J, Hedman K, Nielson L, Dano K, Vaheri A (1988) Ultrastructural localization of plasma membrane associated urokinase-type plasminogen activator at focal contacts. J Cell Biol 106:87-95.

Pyke C, Kristensen P, Ralfkjaer E, Grondahl-Hansen J, Eriksen J, Dano K (1991) Urokinase-type plasminogen activator is expressed in stromal cells and its receptor in cancer cells at invasive foci in human colon adenocarcinomas. Am J Pathol 138:1059-1067.

Raivich G, Kreutzberg W (1993) Peripheral nerve regeneration: role of growth factors and their receptors. Int J Dev Neurosci 11:311-324.

Rao N, Shi G, Chapman H (1995) Urokinase receptor is a multifunctional protein: influence of receptor occupancy on macrophage gene expression. J Clin Invest 96:465-474.

Rogister B, Delree P, Leprince P, Martin D, Sadzot C, Malgrange B, Munaut C, Rigo J, Lefebvre P, Octave N, Schoenen J, Moonen G (1993) Transforming growth factor $\beta$ as a neuronoglial signal during peripheral nervous system response to injury. J Neurosci Res 34:32-43.

Schafer B, Maier K, Eickhoff U, Todd R, Kramer M (1994) Plasminogen activators in healing human wounds. Am J Pathol 144:1269-1280.

Seeds N, Friedman G, Hayden S, Thewke C, Haffke S, McGuire P, Krystosek A (1996) Plasminogen activators and their interaction with the extracellular matrix in neural development, plasticity and regeneration. Semin Neurosci 8:405-412.

Shetty S, Kumar A, Johnson A, Pueblitz S, Holiday D, Raghu G, Idell S (1996) Differential expression of the urokinase receptor in fibroblasts from normal and fibritic human lungs. Am J Respir Cell Mol Biol $15: 78-87$.

Siconolfi L, Seeds N (1997) Induction of plasminogen activatordependent activity during peripheral nerve regeneration. Soc Neurosci Abstr 23:1451.

Siconolfi L, Seeds N (2001) Mice lacking tPA, uPA, or plasminogen genes showed delayed functional recovery after sciatic nerve crush. J Neurosci 21:4348-4355.

Simmons D, Arriza J, Swanson L (1989) A complete protocol for in situ hybridization of messenger RNAs in brain and other tissues with radiolabeled single-stranded RNA probes. J Histotech 12:169-181.

Smirnova I, Ma J, Citron B, Ratzlaff K, Gregory E, Akaabourne M, Festoff B (1996) Neural thrombin and protease nexin I kinetics after murine peripheral nerve injury. J Neurochem 67:2188-2198.

Son Y, Thompson W (1995) Schwann cell processes guide regeneration of peripheral axons. Neuron 14:125-132.

Sumi Y, Dent M, Owen D, Seeley P, Morris R (1992) The expression of tissue and urokinase-type plasminogen activators in neural development suggests different modes of proteolytic involvement in neuronal growth. Development 116:625-637.

Takahashi H, Uno S, Watanabe Y, Arakawa K, Nakagawa S (2000) Expression of nerve growth factor-induced type 1 plasminogen activator inhibitor (PAI-1) mRNA is inhibited by genistein and wortmannin. NeuroReport 11:1111-1115.

Torigoe K, Tanaka H, Takahashi A, Awaya A, Hashimoto K (1996) Basic behavior of migratory Schwann cells in peripheral nerve regeneration. Exp Neurol 137:301-308.

Varani J, Sitrin R, Hillegas W (1992) Expression of plasminogen activator and plasminogen activator inhibitor mRNA in human fibroblasts grown on different substrates. Cytotechnology 9:157-162.

Vassalli J, Baccino D, Belin D (1985) A cellular binding site for the $\mathrm{M}_{\mathrm{r}}$ 55,000 form of the human plasminogen activator urokinase. J Cell Biol 100:86-92.

Verdú E, Navarro X (1997) Comparison of immunohistochemical and functional reinnervation of skin and muscle after peripheral nerve injury. Exp Neurol 146:187-198.

Verrall S (1989) Characterization and purification of tissue plasminogen activator and its binding to the surface of cerebellar neurons. PhD thesis, University of Colorado Health Sciences Center.

Verrall S, Seeds N (1988) Tissue plasminogen activator binding to mouse cerebellar granule neurons. J Neurosci Res 21:420-425.

Verrall S, Seeds N (1989) Characterization of ${ }^{125}$ I-tissue plasminogen activator binding to cerebellar granule neurons. J Cell Biol 109:265-271.

Wei Y, Lukashev M, Simon D, Bodary S, Rosenberg S, Doyle M, Chapman H (1996) Regulation of integrin function by the urokinase receptor. Science 273:1551-1555.

Wilson E, Francis G (1987) Differentiation-linked secretion of urokinase and tissue plasminogen activator by normal human hemopoietic cells. J Exp Med 165:1609-1623.

Xiao Y, Bunn C, Bartold P (1998) Immunohistochemical demonstration of the plasminogen activator system in human gingival tissues and gingival fibroblasts. J Periodontal Res 33:17-26.

Yamamoto Y, Livet J, Pollock R, Garces A, Arce V, deLapeyriere O, Henderson C (1997) Hepatocyte growth factor (HGF/SF) is a musclederived survival factor for a subpopulation of embryonic motoneurons. Development 124:2903-2913.

Yang X, Toma J, Bamji S, Belliveau D, Kohn J, Park M, Miller F (1998) Autocrine hepatocyte growth factor provides a local mechanism for promoting axonal growth. J Neurosci 18:8369-8381.

Zuo J, Ferguson T, Hernandez Y, Stetler-Stevenson W, Muir D (1998) Neuronal matrix metalloproteinase-2 degrades and inactivates a neurite-inhibiting chondroitin sulfate proteoglycan. J Neurosci 18:5203-5211. 